\title{
OBITUARY
}

\section{John Stuart Garrow 19 April 1929-22 June 2016}

European Journal of Clinical Nutrition (2016) 70, 1219-1220; doi:10.1038/ejen.2016.205

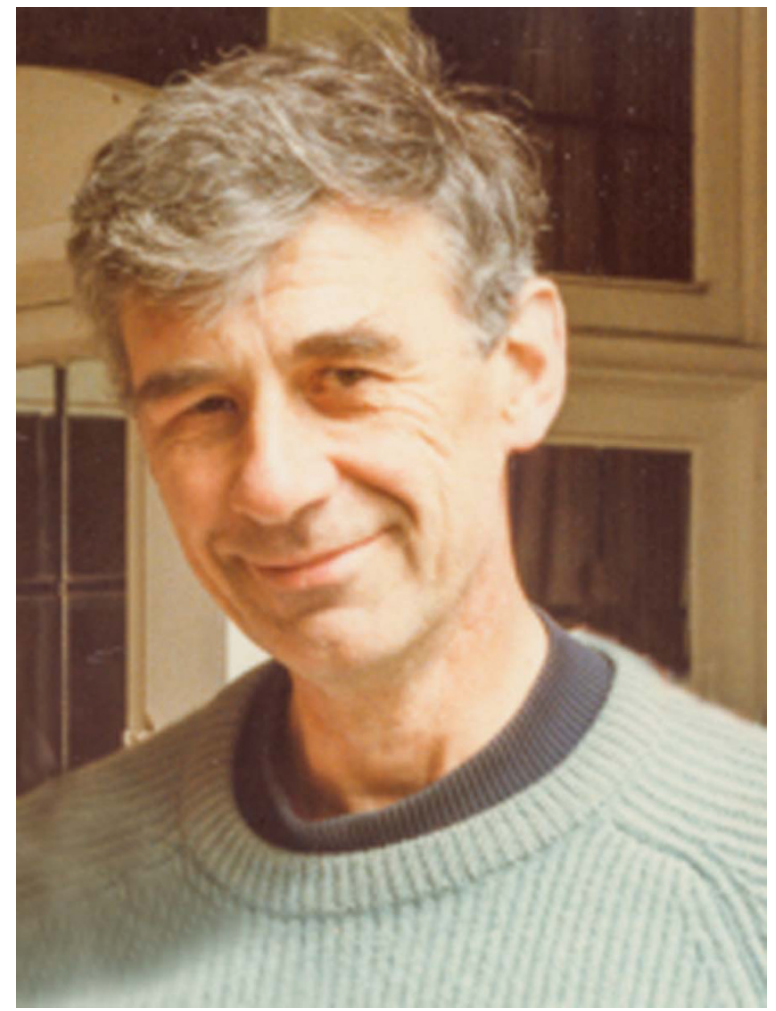

Former Editor-in-Chief, European Journal of Clinical Nutrition.

Professor John Garrow, the first Editor-in-Chief of the European Journal of Clinical Nutrition (EJCN) from 1990 to 1999 passed away on 22 June 2016. He was joint editor with John Waterlow for 2 years prior to that when the two journals Human Nutrition: Clinical Nutrition and Human Nutrition: Applied Nutrition merged in January 1988 to form EJCN. He was the embodiment of scholarly enterprise, clear thinking, clarity and precision in writing, intellectual rigour and integrity. He contributed immensely to the growth of this journal in its first decade, resulting in it emerging as an important and independent vehicle for dissemination of the progress of nutritional research in Europe and outside. The journal owes a deep debt of gratitude to the standards he set very early as its first Editor, and those of us who have had the privilege to succeed him in this post have always had to strive hard to retain the quality and reputation of the journal.

John Garrow was born in Dundee, Scotland, to parents who were both doctors. Following his qualification as a doctor from the University of St Andrews, he continued his training in Jamaica where he met his future wife Katherine who was working there as a paediatrician. His work there on sick malnourished children and his close association with John Waterlow undoubtedly kindled his lifelong serious interest in human nutrition-a discipline to which he made significant contributions. Garrow's work on the body composition of malnourished infants and children at the Tropical Metabolism Research Unit (TMRU) in Jamaica lead to his receiving his MD degree in 1957. He was subsequently awarded a PhD in 1961 for his research on the effect of acceleration on antidiuretic hormone carried out while doing his national service at the RAF Institute for Aviation Medicine at Farnborough.

For many years, John Garrow served as Acting Director of the TMRU in Jamaica and as Scientific Secretary of the Caribbean Medical Research Council's Standing Advisory Committee for Medical Research until his appointment in 1969 as Head of the Nutrition Research Unit of the Medical Research Council's (MRC) Clinical Research Centre (CRC) and as Honorary Consultant at Northwick Park Hospital in London. In 1987, he was appointed to the first Rank Professorship of Human Nutrition in the United Kingdom based at the St Bartholomew's Hospital Medical School. He chaired numerous government committees on nutrition, nutrition education and obesity, and the most important of which included his chairing the Committee on Medical Aspects (COMA) of Food Policy, the Joint Advisory Committee on Nutrition Education (JACNE) and the Association for the Study of Obesity (ASO). John Garrow was also an important member of the MRC/DHSS Joint Working Party chaired by John Waterlow, which produced the first official UK document in 1976 to draw attention to the public health aspects of obesity, which was subsequently even cited by the National Institute of Health $(\mathrm{NIH})$ Report, Obesity in America in 1979. He was also instrumental in persuading the Deans of London's various medical schools and elsewhere to increase the teaching of nutrition to medical students.

When John Garrow returned to the United Kingdom and directed the research at the CRC at Northwick Park, his research interests had moved to the other end of the malnutrition spectrum - to the study of obesity. He recognized quite early on that obesity would become an important clinical and public health problem in the Western world. During this extensive and productive research period (over 20 years) in the United Kingdom-that was internationally acclaimed-he contributed to both the scientific and clinical aspects of obesity. He established facilities for calorimetry, measurement of body composition and metabolic studies in humans at the CRC in Northwick Park to advance the study of this field and trained a wide range of individuals. He not only gained a reputation for his numerous wellresearched scholarly papers, but also for his books, which were characterized by erudition, precision and clarity so uniquely his own. He was the author of well-read books on this topic that include Energy Balance and Obesity in Man, Treating Obesity Seriously: A Clinical Manual, and Obesity and Related Diseases. Along with Philip James, he also edited several editions of the classic textbook Human Nutrition and Dietetics.

John Garrow belonged to the generation that believed in the tradition of self-experimentation or being the first among volunteers for research studies. A few that stand out are his use of the dye Evans blue as tracer for plasma albumin, which incidentally turned his skin blue, and the numerous muscle biopsies he had when he was studying the effects of weight gain on himself! He was also credited by his colleagues as being an innovator and inventor. Examples include his demonstration of a simple 'milk diet' and 'jaw wiring' for weight loss, and his method for removing the zero bias when measuring blood pressure with a sphygmomanometer and the calibration of an instrument for measuring potassium levels. He undoubtedly deserves the credit 
for being the first person to provide a classification of adult obesity for clinical purposes based on body mass index-that he always referred to as Quetelet's index and thus gave credit to the 19th century Belgian astronomer and mathematician Adolphe Quetelet who first described this relationship between body weight and the square of height.

In his later years, John Garrow-a firm believer of evidencebased medicine-was involved in exposing scientific frauds, and became an active member and Chairman for three terms of HealthWatch (formerly known as Campaign Against Health Fraud). His unstinted support for cardiologist Dr Peter Wilmhurst who blew the whistle on the findings of a research trial by NMT Medical is yet another facet of his personality.

John Garrow was a quiet, kind and generous person. He was always courteous even when he disagreed with what you said or presented at a meeting. His intellectual integrity and honesty were outstanding features of his science, and this combined with the clarity of his thinking and writing stood out as an example to researchers and students who were fortunate to meet and speak with him. I was privileged to have known him and interacted with him on several occasions, in addition to the fact that he was my examiner for my PhD in Cambridge, and I also had the rare honour to follow him as Editor-in-Chief of EJCN in 2006 after he handed over the baton to Jaap Siedell in January 2000.

Dr Katherine Garrow, his wife, predeceased him in 2008 and he leaves four children.

P Shetty

Leveraging Agriculture for Nutrition in South Asia (LANSA) MS Swaminathan Research Foundation, Chennai, India E-mail: prakash.s.shetty@gmail.com 